\title{
Insight into the rapid growth of graphene single crystals on liquid metal via chemical vapor deposition
}

\author{
Shuting Zheng ${ }^{1}$, Mengqi Zeng ${ }^{1 *}$, Hui Cao ${ }^{1}$, Tao Zhang ${ }^{1}$, Xiaowen Gao ${ }^{1}$, Yao Xiao ${ }^{2}$ and Lei Fu ${ }^{1,2^{*}}$
}

\begin{abstract}
Previous reports about the growth of large graphene single crystals on polycrystalline metal substrates usually adopted the strategy of suppressing the nucleation by lowering the concentration of the feedstock, which greatly limited the rate of the nucleation and the sequent growth. The emerging liquid metal catalyst possesses the characteristic of quasi-atomically smooth surface with high diffusion rate. In principle, it should be a naturally ideal platform for the lowdensity nucleation and the fast growth of graphene. However, the rapid growth of large graphene single crystals on liquid metals has not received the due attention. In this paper, we firstly purposed the insight into the rapid growth of large graphene single crystals on liquid metals. We obtained the millimeter-size graphene single crystals on liquid $\mathrm{Cu}$. The rich free-electrons in liquid $\mathrm{Cu}$ accelerate the nucleation, and the isotropic smooth surface greatly suppresses the nucleation. Moreover, the fast mass-transfer of carbon atoms due to the excellent fluidity of liquid $\mathrm{Cu}$ promotes the fast growth with a rate up to $79 \mu \mathrm{m} \mathrm{s}^{-1}$. We hope the research on the growth speed of graphene on liquid $\mathrm{Cu}$ can enrich the recognition of the growth behavior of two-dimensional (2D) materials on the liquid metal. We also believe that the liquid metal strategy for the rapid growth of graphene can be extended to various $2 \mathrm{D}$ materials and thus promote their future applications in the photonics and electronics.
\end{abstract}

Keywords: graphene, single crystal, rapid growth, liquid metal, chemical vapor deposition

\section{INTRODUCTION}

Due to the marvelous physical and chemical properties, graphene with one atom thickness can be widely used in photonics and electronics [1-4]. What should be noted is that the reliable application is based on the premise of synthesizing high-quality graphene with high efficiency [5]. The grain boundaries and defects that are inherent in the polycrystalline film will have a strong influence on the mechanical properties and electronic and heat transport in graphene. Therefore, large graphene single crystals are highly demanded for the future applications. Chemical vapor deposition (CVD) approach is regarded as the most promising method to obtain high-quality large-size graphene single crystals [6-9].

Many studies focusing on the growth of graphene single crystal on metal substrates usually adopted the strategy of suppressing the nucleation density by lowering the concentration of the feedstock. However, according to the classical two-dimensional (2D) crystal nucleation and growth theory, when given the insufficient feedstock, although only a small amount of atom clusters can reach the critical size and initiate the nucleation, the rate of the nucleation and the sequent growth will be simultaneously limited significantly. Obviously, an ideal synthesis of graphene single crystal involving the rapid nucleation with low density and rapid growth is urgently to be established. The substrate design should be the sally port since it determines the adsorption, diffusion and assembly steps in the CVD process.

In the usual case studied on the polycrystalline solid $\mathrm{Cu}$, the nucleation of crystal preferentially occurs at the sites with high surface energy, such as the grain boundaries, defect sites, facet steps and impurities because the free electrons at the metal surface can significantly saturate graphene edges [10], inevitably leading to the inhomogeneous nucleation density and limited crystal size $[5,11]$. Previous studies $[12,13]$ on the growth of large graphene single crystals mainly focused on the improvement of surface morphology and the decrease of chemical reactivity of the substrate assisted with relatively low input of feedstock, such as surface monocrystallization and surface oxidation passivation, leading to a retarded growth rate. It is notable that by

${ }^{1}$ College of Chemistry and Molecular Sciences, Wuhan University, Wuhan 430072, China

${ }^{2}$ Institute for Advanced Studies (IAS), Wuhan University, Wuhan 430072, China

* Corresponding authors (emails: zengmq_lan@whu.edu.cn (Zeng M); leifu@whu.edu.cn (Fu L)) 
continuously supplying oxygen, the energy barrier of the decomposition of the carbon feedstock is enormously reduced and the growth rate of graphene reaches up to $60 \mu \mathrm{m} \mathrm{s}^{-1}[14,15]$. However, the size of the as-obtained graphene single crystals is limited to several hundreds of micrometers. In addition, locally feeding carbon precursors at a desired position is beneficial to the single nucleation and fast growth of graphene [16]. While such a strategy requires complicated design and experimental setup and the growth rate is also not so satisfying. So far, how to achieve the low-density nucleation and fast growth for large-size graphene single crystal remains a great challenge.

The emerging liquid metal catalyst possesses the characteristic of quasi-atomically smooth surface with high diffusion rate, which can avoid the defects and grain boundaries that are inevitable for solid $\mathrm{Cu}$ [17-19]. In principle, it should be a naturally ideal platform for the low-density nucleation and the fast growth of graphene. A good balance between the nucleation density and the growth rate can be achieved. However, the rapid growth of large graphene single crystal on liquid $\mathrm{Cu}$ has not received due attention. Here, we firstly purposed the insight into the rapid growth of large graphene single crystal on liquid metal. We have obtained millimeter-size high-quality graphene single crystal on liquid $\mathrm{Cu}$. The rich free electrons in liquid $\mathrm{Cu}$ accelerate the nucleation of graphene, and in the meantime the isotropic smooth surface greatly suppresses the nucleation density. Moreover, the fast mass-transfer of carbon atoms due to the excellent fluidity of liquid $\mathrm{Cu}$ promotes the fast growth with a rate up to $79 \mu \mathrm{m} \mathrm{s}^{-1}$. We hope that our work on the growth speed of graphene on liquid $\mathrm{Cu}$ system can further extend the roadmap of the growth behavior of $2 \mathrm{D}$ materials on the liquid metal. We also believe that the liquid metal strategy for the rapid growth of graphene can be extended to various $2 \mathrm{D}$ materials and thus promote their future applications.

\section{EXPERIMENTAL SECTION}

\section{CVD growth of graphene single crystal on liquid $\mathrm{Cu}$}

The commercial $\mathrm{Cu}$ foils with a thickness of $100 \mu \mathrm{m}$ (99.999\%, Alfa Aesar) and W foils (99.95\%, Alfa Aesar) with a thickness of $100 \mu \mathrm{m}$ were used to form liquid $\mathrm{Cu}$ $\mathrm{W}$ substrate. One piece of $1 \times 1 \mathrm{~cm}^{2} \mathrm{Cu}$ foil was directly put onto the $1 \times 1 \mathrm{~cm}^{2} \mathrm{~W}$ foil, and then they were placed in the center of the furnace (Lindberg/Blue M, HTF55322C) with $800 \mathrm{sccm}$ (standard cubic centimeters per minute) Ar to clean the growth system. Then the stacked $\mathrm{Cu} / \mathrm{W}$ foils were heated to $1,086-1,120^{\circ} \mathrm{C}$ in the atmosphere of Ar and $\mathrm{H}_{2}$. When the temperature was up to the target temperature, the solid $\mathrm{Cu}$ foil was melted into a liquid state and spread on the $\mathrm{W}$ foil. During the growth process of graphene, $\mathrm{CH}_{4}$ with different flow rates was introduced for different durations. After finishing the growth, the $\mathrm{CH}_{4}$ was turned off, and the furnace was naturally cooled down to room temperature.

\section{Transfer of graphene single crystal grown on liquid $\mathrm{Cu}$}

The graphene was transferred onto the $300 \mathrm{~nm} \mathrm{SiO} / \mathrm{Si}$ substrate by employing the 'bubbling transfer' method for Raman and electrical measurement [20]. The $\mathrm{Cu}-\mathrm{W}$ substrate covered by graphene was spin-coated with polymethylmethacrylate (PMMA) at a speed of 3,000 $\mathrm{rpm}$, and then was baked at $170^{\circ} \mathrm{C}$ for $10 \mathrm{~min}$. Subsequently, in the electrochemical bubbling process, the $\mathrm{Cu}-\mathrm{W}$ substrate acted as a cathode, and a platinum foil was used as the anode. $\mathrm{NaOH}$ solution $\left(1 \mathrm{~mol} \mathrm{~L}^{-1}\right)$ served as the electrolyte. A constant current of $0.05 \mathrm{~A}$ supplied by a direct current power (DH1720A-5) was employed to release the PMMA/graphene film from the $\mathrm{Cu}-\mathrm{W}$ substrate. After that, the PMMA/graphene film was transferred onto the $\mathrm{SiO}_{2} / \mathrm{Si}$ substrate and then was dried naturally followed by the removal of PMMA in the hot acetone. When TEM characterization was conducted, the PMMA/graphene film was transferred onto the $\mathrm{Cu}$ grid and the subsequent steps were the same.

\section{Electrical measurement}

The ultraviolet lithography was employed to get the electrode pattern. Subsequently, $5 \mathrm{~nm} \mathrm{Ti}$ and $45 \mathrm{~nm} \mathrm{Au}$ electrodes were successively deposited by thermal evaporation. The data of current $(I)$-voltage $(V)$ were collected in a probe station (Keithley 4200) at room temperature under air.

\section{Characterization}

Optical images were taken with an optical microscope (Olympus DX51). Raman spectra and maps were collected with a micro-Raman spectrometer (Renishaw in Via, $532 \mathrm{~nm}$ excitation wavelength). Scanning electron microscopy (SEM) images were taken by a ZEISS Merlin Compact SEM. Transmission electron microscopy (TEM) images, corresponding selected area electron diffraction (SAED) patterns and high-resolution atomic images were obtained by a high-resolution TEM (JEM-2100) with the operating voltage of $200 \mathrm{kV}$ and aberration-corrected high-resolution TEM (Model AC-HRTEM, FEI Titan) with the operating voltage of $80 \mathrm{kV}$. Electron back- 

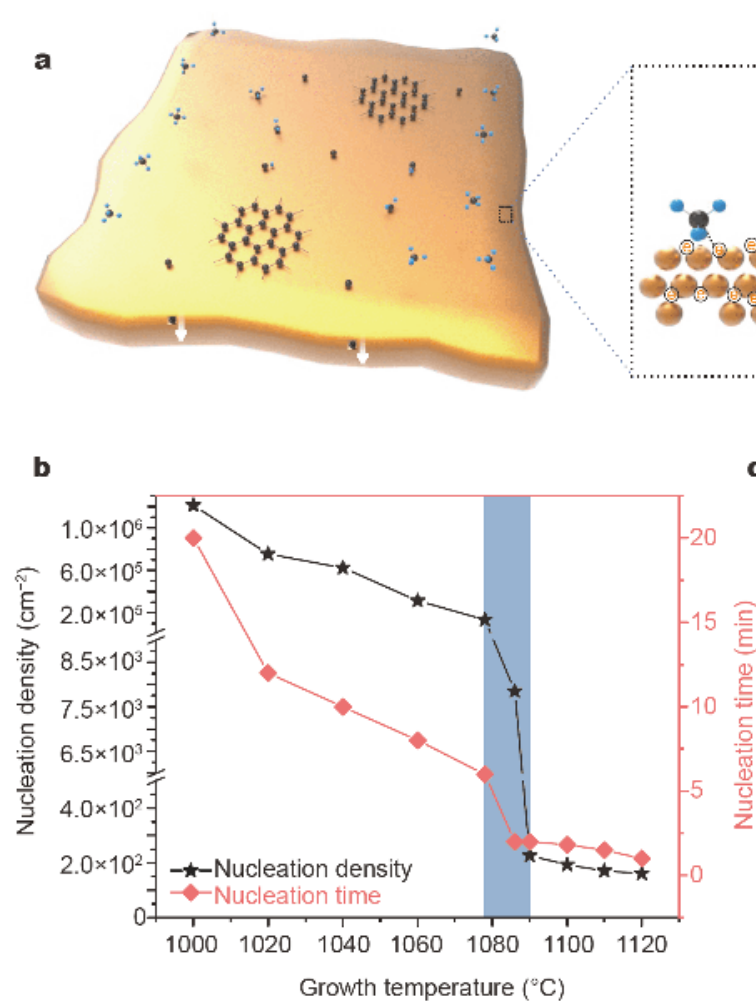
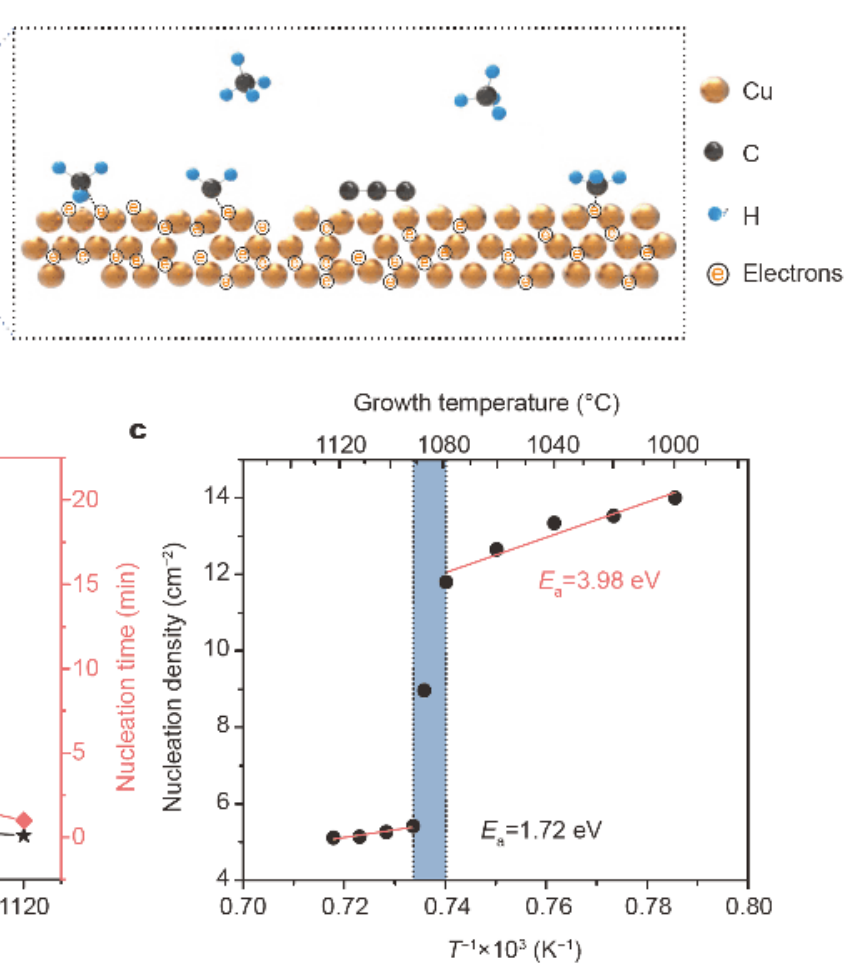

Figure 1 The nucleation of graphene on liquid $\mathrm{Cu}$. (a) Schematic of the graphene nucleation on liquid $\mathrm{Cu}$ under $\mathrm{CH}_{4}$ with extremely low concentration. The rich free electrons in liquid $\mathrm{Cu}$ can help grab the active carbon species for the graphene nucleation. (b) Plot of the nucleation density and nucleation time of graphene on $\mathrm{Cu}$ as a function of the temperature. (c) Arrhenius plot for the nucleation density of graphene on Cu.

scattered diffraction (EBSD) characterization was carried out by QUANTA FEG 450 at the operating voltage of $20 \mathrm{keV}$. The time of flight secondary ion mass spectra (TOF-SIMS) and maps were collected with ION-TOF (TOF SIMS 5). $\mathrm{A} \mathrm{Cs}^{+}$ion beam with the energy of $2 \mathrm{keV}$ was employed to remove the layer while a $\mathrm{Bi}^{3+}$ ion beam with the energy of $30 \mathrm{keV}$ was performed to analyze the material composition.

\section{RESULTS AND DISCUSSION}

Firstly, the nucleation of graphene on liquid $\mathrm{Cu}$ was investigated. $\mathrm{CH}_{4}$ at an extremely low concentration (0.5 $\mathrm{sccm} / 300 \mathrm{sccm} / 50 \mathrm{sccm} \mathrm{CH}_{4} / \mathrm{Ar} / \mathrm{H}_{2}$ ) was introduced to critically trigger the nucleation. Fig. 1a illustrates the schematic diagram of the nucleation of graphene on liquid $\mathrm{Cu}$ surface. Fig. $1 \mathrm{~b}$ shows the nucleation density and the nucleation time of graphene grains as a function of the growth temperature. Here, the nucleation time is defined as the duration time from the moment when $\mathrm{CH}_{4}$ is introduced to the CVD furnace to the time when the graphene grains reach several microns. The typical SEM images corresponding to the graphene nucleation at the temperature ranging from 1,000 to $1,120^{\circ} \mathrm{C}$ are shown in
Fig. S1, from which the nucleation density can be statistically derived. The nucleation density of graphene is as high as $1.21 \times 10^{6} \mathrm{~cm}^{-2}$ at the temperature of $1,000{ }^{\circ} \mathrm{C}$ on solid $\mathrm{Cu}$ with the nucleation time of $20 \mathrm{~min}$, which is in the same order of magnitude with the previously reported studies [21-23]. With the temperature increasing from 1,000 to $1,060^{\circ} \mathrm{C}$, the $\mathrm{Cu}$ keeps in a solid state and the nucleation density and nucleation time both decrease smoothly. However, when the heating temperature increases from 1,078 to $1,086^{\circ} \mathrm{C}$, approaching the melting point of $\mathrm{Cu}\left(1,083^{\circ} \mathrm{C}\right), \mathrm{Cu}$ begins to melt and the nucleation density of graphene exhibits a sharp decline with two orders of magnitude, and the nucleation time reduces from 6 to $2 \mathrm{~min}$. As the temperature further increases, the nucleation density of graphene on liquid $\mathrm{Cu}$ starts to decline very slowly and finally reaches $2.26 \times 10^{2} \mathrm{~cm}^{-2}$. It is obvious that both the nucleation density and nucleation time of the graphene grains exhibit a significant improvement along with the phase transition of the $\mathrm{Cu}$. To evaluate the activation energy of the nucleation, Arrhenius function for the nucleation density of graphene on liquid $\mathrm{Cu}$ with temperature was conducted (Fig. 1c). For the nucleation on solid $\mathrm{Cu}$, the 
as-derived activation energy $\left(E_{\mathrm{a}}\right)$ is $3.98 \mathrm{eV}$, while for that on liquid $\mathrm{Cu}$, the as-derived value is $1.72 \mathrm{eV}$. There indeed exists a significant difference of activation barrier between solid $\mathrm{Cu}$ and liquid $\mathrm{Cu}$. The growth of graphene single crystals possesses a shorter nucleation time and a lower nucleation density on liquid $\mathrm{Cu}$ than on solid $\mathrm{Cu}$.

To understand the difference between the graphene nucleation on solid $\mathrm{Cu}$ and liquid $\mathrm{Cu}$, a deep insight into the elemental steps in the CVD process must be explored. Typical nucleation and growth stage of graphene are expected to experience the following elementary steps: (i) the adsorption of gas precursors; (ii) dehydrogenation of precursors on the catalyst substrates, leading to the formation of active carbon species; (iii) the diffusion of active carbon species; (iv) the formation of island with the critical size (critical nucleus), competing against the desorption; (v) the further growth of critical nucleus by incorporating $C$ species to the graphene lattice [7-9].

With a low concentration carbon source, in the early stage of the nucleation, the carbon clusters were not stable and their energy tended to increase with the number of carbon atoms, leading to their decomposition. Only a small number of clusters can reach the critical size $\left(n^{*}\right)$ with the Gibbs free energy increasing to the maximum value, which was the potential barrier in the nucleation of graphene. When the size of the clusters exceeded $n^{*}$, the Gibbs free energy started to decline with the enlargement of the clusters. The subsequent growth of the carbon clusters became faster than the nucleation. Therefore, the nucleation barrier determines the nucleation process, including the nucleation incubation time and the nucleation density.

The nucleation of graphene on solid $\mathrm{Cu}$ tends to occur at the active steps or defects rather than the terrace since the graphene edge can be saturated more effectively at these sites by the free electrons on the metal surface. Therefore, the nucleation density of graphene on solid $\mathrm{Cu}$ with a number of defects will be very high, leading to the graphene film with tremendous defects $[24,25]$. When the solid $\mathrm{Cu}$ surface is smoothened, the high nucleation potential barrier will hamper the high-efficiency nucleation. With the increase of the chemical potential of carbon (the concentration of the carbon precursor), the nucleation potential barrier will be totally overcome irrespective of the steps or terrace, leading to the nucleation with high density. It is nearly impossible to achieve the fast nucleation with low density.

However, the nucleation on liquid $\mathrm{Cu}$ with a fast speed and low density can be effectively achieved, attributed to the difference of electronic state and surface structure between liquid $\mathrm{Cu}$ and solid $\mathrm{Cu}$. On one hand, compared with the localization of d-electrons in the crystalline state, the delocalization of d-electrons occurs in a disordering state. There is a redistribution of the density of delectrons among the neighbor atoms in liquid $\mathrm{Cu}$ [2628]. Liquid metal is composed of positive ions which are scattered in the sea of electrons [29]. As shown in Fig. 1a, these rich free electrons on the liquid metal surface can significantly saturate the graphene edges and passivate the carbon clusters, and thus the formation energy of carbon clusters can be significantly lowered, which facilitates the fast nucleation $[9,10]$. The atom clusters would prefer to stably stick to liquid $\mathrm{Cu}$ surface rather than to re-vaporize during the deposition process. On the other hand, the surface of liquid $\mathrm{Cu}$ is isotropic and smooth, and the initial nucleation density will be quite low. In order to clarify the difference of the substrate surface structure between solid $\mathrm{Cu}$ and liquid $\mathrm{Cu}, \mathrm{EBSD}$ was conducted on the solid $\mathrm{Cu}$ foil and the $\mathrm{Cu}$ foil after liquefaction and solidification, as seen in Fig. S2. Compared with the polycrystalline nature of solid $\mathrm{Cu}$ surface, the surface of solidified liquid $\mathrm{Cu}$ exhibits nearly uniform single crystal characteristic, which can act as a perfect platform to avoid defects and grain boundaries for low-density nucleation. In addition, when the size of the carbon clusters exceeds the critical nuclear size, the increment of Gibbs free energy will reduce with the increase of the carbon atoms. The graphene growth turns into a kinetic dominating process and the active carbon species prefers to attach to the edge of the already existing nuclei for graphene growth, rather than form new nuclei [30,31]. Thus, a rapid nucleation with a low nucleation density of graphene is achieved on liquid $\mathrm{Cu}$.

Then, the growth of graphene on liquid $\mathrm{Cu}$ was systematically investigated. Fig. 2a-c present the SEM images of the individual graphene single crystals obtained at different growth time on liquid $\mathrm{Cu}$ at the temperature of $1,120^{\circ} \mathrm{C}$. Here, the growth time of graphene is defined by the feeding time of $\mathrm{CH}_{4}$. At the growth time of $2 \mathrm{~s}$, graphene grains with a size of $\sim 5 \mu \mathrm{m}$ can be clearly observed by SEM (Fig. 2a), confirming the rapid nucleation of graphene on liquid $\mathrm{Cu}$ surface again. The size of graphene quickly increases to $\sim 33 \mu \mathrm{m}$ at the growth time of $3 \mathrm{~s}$ (Fig. 2b), and further reaches to $\sim 112 \mu \mathrm{m}$ at the growth time of $4 \mathrm{~s}$ (Fig. 2c). The maximum growth speed is as high as $79 \mu \mathrm{m} \mathrm{s}^{-1}$, which is faster than those reported in the previous work in Fig. 2e and Table S1 [12-14,16,30,32-35]. To the best of our knowledge, this is the first exploration of such exceptionally fast growth of graphene single crystal on 

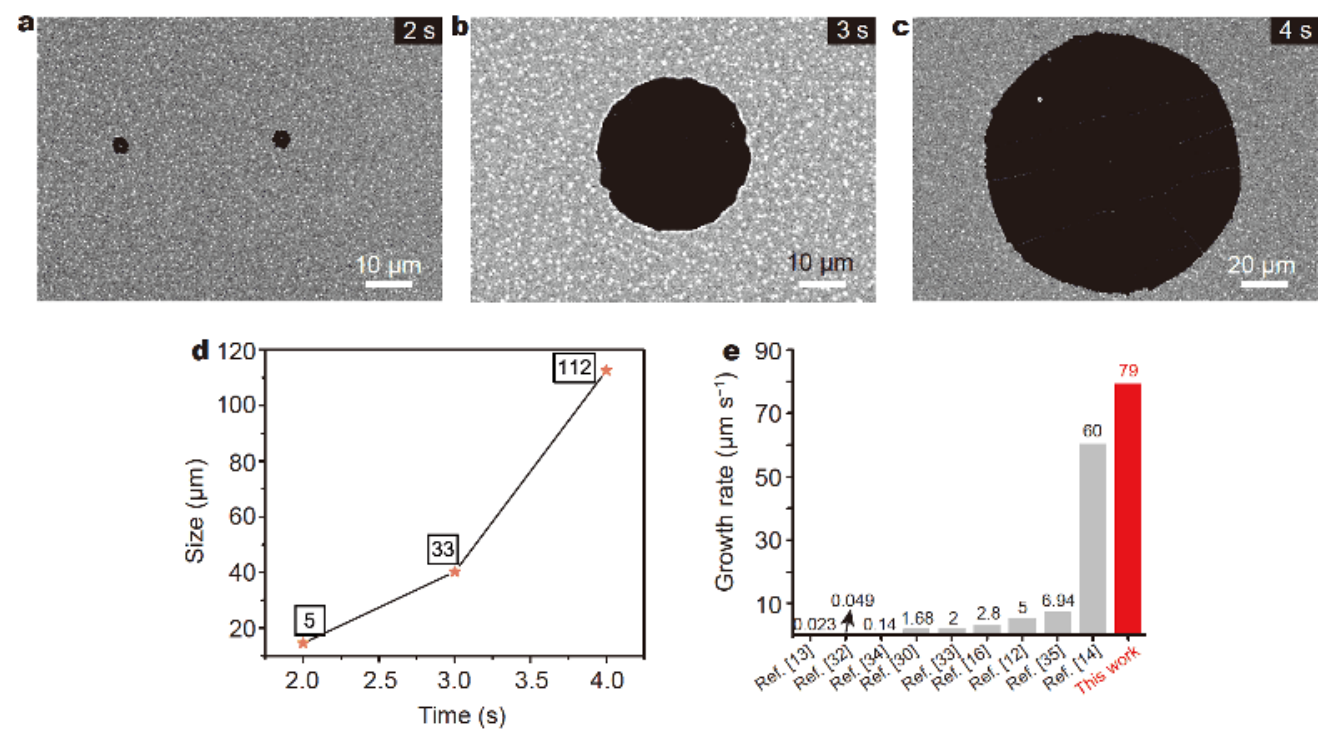

Figure 2 Time evolution of graphene single crystal grown on liquid $\mathrm{Cu}$. (a-c) SEM images of graphene single crystals synthesized at $t=2,3$ and $4 \mathrm{~s}$. $t=$ $0 \mathrm{~s}$ is defined as the moment when $\mathrm{CH}_{4}$ is introduced to the CVD furnace. (d) Plot of graphene size as a function of growth time. (e) Comparison of the growth rate of graphene in the recent literatures. The growth was conducted in the atmosphere of $\mathrm{Ar} / \mathrm{H}_{2} / \mathrm{CH}_{4}(800 \mathrm{sccm} / 5 \mathrm{sccm} / 5 \mathrm{sccm})$ at $1,120^{\circ} \mathrm{C}$.

liquid $\mathrm{Cu}$ surface, which encourages us to study the kinetics of fast growth of graphene single crystal. By contrast, the growth of graphene single crystal on solid $\mathrm{Cu}$ was also analyzed, as seen in Fig. S3. It can be seen that the nucleation time of graphene on solid $\mathrm{Cu}$ is much slower than that on liquid $\mathrm{Cu}$. The growth rate of graphene on liquid $\mathrm{Cu}$ is almost two orders larger than that on solid $\mathrm{Cu}$. The rapid growth of graphene single crystal on liquid $\mathrm{Cu}$ can be ascribed to the following aspects.

First of all, the nucleation density of graphene on liquid $\mathrm{Cu}$ is greatly reduced [36], favorable for the fast growth since the dissociative decomposed carbon atoms on the fluidic liquid $\mathrm{Cu}$ surface tend to attach to the as-formed graphene islands instead of forming new nuclei. Secondly, the evaporation of $\mathrm{Cu}$ atoms is much more pronounced for liquid $\mathrm{Cu}$ than that for solid $\mathrm{Cu}$ [37]. The collision between the copper vapor originating from liquid $\mathrm{Cu}$ and $\mathrm{CH}_{4}$ gas is greatly enhanced, promoting the decomposition of $\mathrm{CH}_{4}$ and producing highly active carbon species. Subsequently, the as-decomposed carbon atoms are prone to incorporate into the existing graphene islands. Thirdly, the migration potential barrier of precursors on liquid $\mathrm{Cu}$ is far lower than that on solid substrates. Liquid $\mathrm{Cu}$ exhibits a short-range order but a long-range disorder in the atomic configuration and is composed of abundant copper atoms, clusters and vacancies, which can facilitate the embedding of hetero-atoms [38]. Due to the instability of the surface atoms in the clusters, it may transfer from the primary clusters to another, resulting in very weak binding force among the atomic clusters [28]. The intense thermal motion leads to a fluctuation of the interatomic distance and a dynamic change of the distribution of the vacancies, which facilitates the migration of the carbon atoms and increases their diffusion rate. The diffusion mass transport of carbon atoms on the liquid surface plays a significant role in the rate-determining step of graphene growth on liquid $\mathrm{Cu}$. As shown in Fig. S4, when the growth temperature was increased, the surface tension of liquid $\mathrm{Cu}$ decreased and the as-related rate of diffusion of carbon species increased, leading to a higher growth rate and the formation of the larger graphene single crystals. To exclude the effect of the increase of the decomposed carbon concentration with the temperature, we conducted the growth of graphene at a higher flow rate of $\mathrm{CH}_{4}$. As seen in Fig. S5, the growth rate of graphene changes little and the size of the obtained graphene single crystals is nearly the same because the mass-transport via diffusion determined by the temperature is the ratedetermining step for the graphene growth. In addition, to elucidate the mechanism and kinetics of the graphene growth on liquid $\mathrm{Cu}$, carbon isotope labeling experiments were conducted with Raman spectroscopy. Specific Raman $\mathrm{G}$ bands at 1,525 and $1,595 \mathrm{~cm}^{-1}$ correspond to the signals of ${ }^{13} \mathrm{C}$ and ${ }^{12} \mathrm{C}$ graphene, respectively [39]. In 

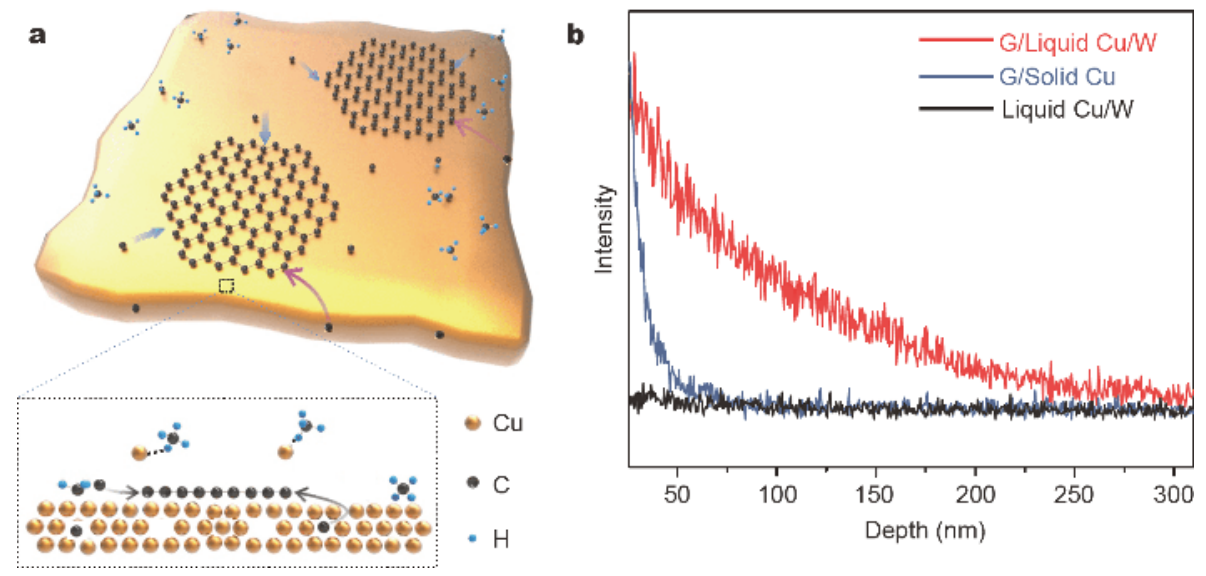

Figure 3 Fast growth mechanism of graphene on liquid $\mathrm{Cu}$. (a) Schematic illustration of the precursor supply for the graphene growth on liquid $\mathrm{Cu}$, which can both come from the surface adsorption and the bulk segregation. (b) TOF-SIMS characterizations to show the intensity profile of carbon along the surface of $\mathrm{G} /$ liquid $\mathrm{Cu}$ and $\mathrm{G} /$ solid $\mathrm{Cu}$ after graphene growth for $10 \mathrm{~min}$, and liquid $\mathrm{Cu}$ after annealing for $10 \mathrm{~min}$, respectively.

the growth of graphene on liquid $\mathrm{Cu},{ }^{13} \mathrm{CH}_{4}$ and ${ }^{12} \mathrm{CH}_{4}$ were sequentially introduced to the reaction zone, and the system was purged with $800 \mathrm{sccm}$ Ar and $50 \mathrm{sccm} \mathrm{H}_{2}$ for 2 min to reduce intermixing of the two isotopes. The statistical data show that the peak position of the G band of the as-obtained graphene is narrowly located at $1,562 \mathrm{~cm}^{-1}$ (Fig. S6a), indicating the uniform distribution of ${ }^{13} \mathrm{C}$ and ${ }^{12} \mathrm{C}$, which is different from the situation for the graphene on the solid $\mathrm{Cu}$ [39]. Unlike the surface adsorption growth mode on solid $\mathrm{Cu}$, the precursor supply for the graphene growth on liquid $\mathrm{Cu}$ can both come from the surface adsorption and the bulk segregation. Due to the rich vacancies in liquid $\mathrm{Cu}$ [38], carbon atoms can firstly diffuse into the metal bulk before segregating and precipitating toward the $\mathrm{Cu}$ surface just as the growth of graphene on $\mathrm{Ni}$ with high carbon solubility [39]. As a result, a uniform distribution of ${ }^{12} \mathrm{C}$ and ${ }^{13} \mathrm{C}$ atoms is expected to be obtained by sequential dosing of ${ }^{12} \mathrm{CH}_{4}$ and ${ }^{13} \mathrm{CH}_{4}$, and the as-produced graphene single crystals are composed of uniformly distributed ${ }^{12} \mathrm{C}$ and ${ }^{13} \mathrm{C}$ atoms, exhibiting the highly mixed G Raman band. Therefore, the precursor supply for the graphene growth on liquid $\mathrm{Cu}$ can be attributed to both the surface diffusion and bulk segregation (Fig. 3a). TOF-SIMS was carried out to exhibit the carbon distribution on the surface and sub-surface of the sample with high-accuracy depth profiling. In this study, depthprofiling SIMS measurements performed on graphene/ liquid $\mathrm{Cu} / \mathrm{W}(\mathrm{G} /$ liquid $\mathrm{Cu})$, graphene/Cu $(\mathrm{G} /$ solid $\mathrm{Cu})$ and $\mathrm{Cu} / \mathrm{W}$ (liquid $\mathrm{Cu}$ ) elaborated the distinctly different carbon dissolution behaviors in the liquid and solid $\mathrm{Cu}$ (Fig. 3b). In the case of $\mathrm{G} /$ liquid $\mathrm{Cu}$, an enrichment of carbon was detected on the surface of liquid $\mathrm{Cu}$ after the substrate was exposed to $\mathrm{CH}_{4}$ for a few minutes. The intensity of carbon content decreases slowly from the surface to the depth of $310 \mathrm{~nm}$. However, a rapid monotonic decrease of carbon content occurs in G/solid $\mathrm{Cu}$ at the same depth analysis, which reveals a rather low saturation state of carbon content in solid $\mathrm{Cu}$. By comparison, the carbon concentration along the profile in the pure liquid $\mathrm{Cu}$ remains the same, which can eliminate the background signal. In addition, carbon atoms sufficiently diffuse into the bulk of liquid $\mathrm{Cu}$ with the intensity map of SIMS shown in Fig. S7a, and there are nearly no carbon atoms diffusing into the bulk of the solid $\mathrm{Cu}$ as shown in Fig. S7b. The results confirm the different bulk segregation behaviors between liquid $\mathrm{Cu}$ and solid $\mathrm{Cu}$. The binary contributions of the precursor supply, i.e., the surface adsorption and the bulk segregation, accelerate the growth of graphene.

Due to the low nucleation density, fast nucleation time and rapid growth rate, we achieved the rapid growth of large graphene single crystals on liquid $\mathrm{Cu}$. As seen in Fig. 4a, graphene single crystals with the diameter of $\sim 2.6 \mathrm{~mm}$ can be seen directly from the naked eye. Fig. $4 \mathrm{~b}$ exhibits the optical microscopy (OM) image of an astransferred graphene crystal on a $300 \mathrm{~nm} \mathrm{SiO}_{2} / \mathrm{Si}$ substrate. The characteristic $2 \mathrm{D}$ and $\mathrm{G}$ bands are displayed with the intensity ratio $\left(I_{2 \mathrm{D}} / I_{\mathrm{G}}\right)$ larger than 2 , exhibiting a monolayer feature. No discernible defectrelated $\mathrm{D}$ band located at $\sim 1,350 \mathrm{~cm}^{-1}$ can be identified, demonstrating the high quality of the as-grown graphene (Fig. S8f) [40,41]. To confirm the single crystal characteristic of the graphene grains, Raman mapping 

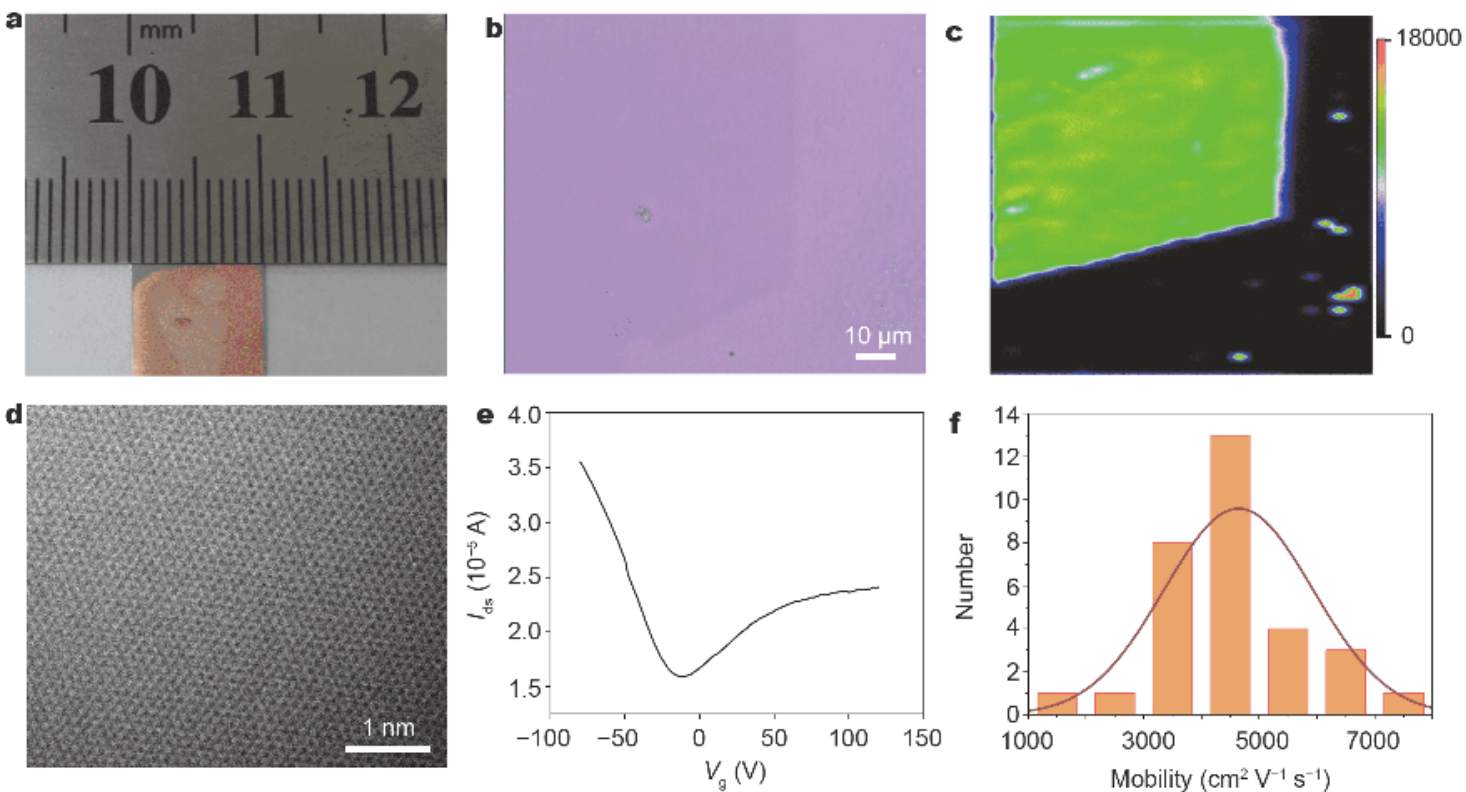

Figure 4 Large graphene single crystals grown on liquid $\mathrm{Cu}$ and the related quality characterizations. (a) Photograph of graphene single crystals grown on liquid $\mathrm{Cu}$. (b) OM image of a corner of graphene single crystal transferred onto $300 \mathrm{~nm} \mathrm{SiO} / 2 \mathrm{Si}$ substrate. (c) Intensity mapping of 2D band, corresponding to the region in (b), showing the uniformity of the graphene single crystal at macroscopic scale. (d) HRTEM image of graphene, revealing the perfect hexagonal honeycomb structure. (e) The typical transfer characteristic curve of the as-fabricated FET device based on the graphene single crystal grown on liquid $\mathrm{Cu}$ at room temperature. (f) A histogram plot of the mobility value distribution extracted from 30 devices.

(Fig. 4c) shows the $2 \mathrm{D}$ intensity mapping of a corner of a graphene crystal with a very uniform contrast, further indicating the high crystallinity of the as-grown large graphene crystal at the macroscopic scale. The microstructure of the graphene single crystal was evaluated by TEM. Single-layer characteristic is determined by counting the dark lines of the backfolded edge (Fig. S8b). The SAED patterns derived from different regions on an individual crystal show the same orientation, demonstrating its single crystalline characteristic (Fig. S8c-e). The single-layer feature and the superior crystallinity of the graphene crystal were further probed by the low-voltage, aberration-corrected, highresolution TEM (Fig. 4d), which clearly revealed the perfect atom-scale six-fold symmetric single-crystal nature of the graphene without any detectable defect and vacancy. The electrical quality of the as-obtained graphene single crystal was evaluated through constructing back-gated field-effect transistors (FET) on $300 \mathrm{~nm}$ $\mathrm{SiO}_{2} / \mathrm{Si}$ substrates. As shown in Fig. 4e, a typical transfer curve of the drain current $\left(I_{\mathrm{ds}}\right)$ as a function of the gate voltage $\left(V_{\mathrm{g}}\right)$ was collected under the ambient condition in the air. In addition, a histogram distribution of the derived carrier mobility value extracted from 30 FET devices is presented in Fig. 4f. The mobility is ranging from 1,000 to $8,000 \mathrm{~cm}^{2} \mathrm{~V}^{-1} \mathrm{~s}^{-1}$, reasonably confirming the high quality of the graphene single crystals grown on liquid $\mathrm{Cu}$.

\section{CONCLUSION}

In summary, we have achieved the rapid growth of millimeter-size graphene single crystals on liquid $\mathrm{Cu}$, taking advantage of the characteristic of liquid metal. The fast nucleation can be attributed to the rich free-electrons in liquid $\mathrm{Cu}$, significantly lowering the nucleation energy barrier. And the low nucleation density is due to the lowdefect and highly homogeneous isotropic liquid surface. The growth rate of the graphene single crystal on liquid $\mathrm{Cu}$ is up to $79 \mu \mathrm{m} \mathrm{s}^{-1}$. And the fast growth is highly dependent on the low nucleation density, high diffusion rate and unique segregation mass-transfer mechanism in liquid $\mathrm{Cu}$ growth system. We believe the exciting results provide a new direction to the fast growth of large $2 \mathrm{D}$ material single crystals on the liquid metals.

Received 29 January 2019; accepted 16 February 2019; published online 15 March 2019

1 Novoselov KS, Geim AK, Morozov SV, et al. Two-dimensional gas of massless Dirac fermions in graphene. Nature, 2005, 438: 197200 
2 Novoselov KS, Fal'ko VI, Colombo L, et al. A roadmap for graphene. Nature, 2012, 490: 192-200

3 Zeng M, Xiao Y, Liu J, et al. Exploring two-dimensional materials toward the next-generation circuits: from monomer design to assembly control. Chem Rev, 2018, 118: 6236-6296

4 Li K, Zhang J. Recent advances in flexible supercapacitors based on carbon nanotubes and graphene. Sci China Mater, 2017, 61: 210232

5 Lin L, Deng B, Sun J, et al. Bridging the gap between reality and ideal in chemical vapor deposition growth of graphene. Chem Rev, 2018, 118: 9281-9343

6 Vlassiouk I, Smirnov S, Regmi M, et al. Graphene nucleation density on copper: fundamental role of background pressure. J Phys Chem C, 2013, 117: 18919-18926

7 Safron NS, Kim M, Gopalan P, et al. Barrier-guided growth of micro- and nano-structured graphene. Adv Mater, 2012, 24: 10411045

8 Kim HK, Mattevi C, Calvo MR, et al. Activation energy paths for graphene nucleation and growth on $\mathrm{Cu}$. ACS Nano, 2012, 6: 36143623

9 Wang L, Gao J, Ding F. Application of crystal growth theory in graphene CVD nucleation and growth. Acta Chim Sin, 2014, 72: 345-358

10 Gao J, Yip J, Zhao J, et al. Graphene nucleation on transition metal surface: structure transformation and role of the metal step edge. J Am Chem Soc, 2011, 133: 5009-5015

11 Geng D, Wang H, Yu G. Graphene single crystals: size and morphology engineering. Adv Mater, 2015, 27: 2821-2837

12 Wang $\mathrm{H}, \mathrm{Xu} \mathrm{X}, \mathrm{Li} \mathrm{J}$, et al. Surface monocrystallization of copper foil for fast growth of large single-crystal graphene under free molecular flow. Adv Mater, 2016, 28: 8968-8974

13 Hao Y, Bharathi MS, Wang L, et al. The role of surface oxygen in the growth of large single-crystal graphene on copper. Science, 2013, 342: 720-723

$14 \mathrm{Xu} \mathrm{X}$, Zhang Z, Qiu L, et al. Ultrafast growth of single-crystal graphene assisted by a continuous oxygen supply. Nat Nanotech, 2016, 11: 930-935

15 Xu X, Zhang Z, Dong J, et al. Ultrafast epitaxial growth of metresized single-crystal graphene on industrial $\mathrm{Cu}$ foil. Sci Bull, 2017, 62: 1074-1080

16 Wu T, Zhang X, Yuan Q, et al. Fast growth of inch-sized singlecrystalline graphene from a controlled single nucleus on $\mathrm{Cu}-\mathrm{Ni}$ alloys. Nat Mater, 2015, 15: 43-47

17 Zeng M, Wang L, Liu J, et al. Self-assembly of graphene single crystals with uniform size and orientation: the first $2 \mathrm{D}$ superordered structure. J Am Chem Soc, 2016, 138: 7812-7815

18 Liu J, Fu L. Controllable growth of graphene on liquid surfaces. Adv Mater, 2018, 8: 1800690

19 Zeng M, Fu L. Controllable fabrication of graphene and related two-dimensional materials on liquid metals via chemical vapor deposition. Acc Chem Res, 2018, 51: 2839-2847

20 Gao L, Ren W, Xu H, et al. Repeated growth and bubbling transfer of graphene with millimetre-size single-crystal grains using platinum. Nat Commun, 2012, 3: 699

21 Hedayat SM, Karimi-Sabet J, Shariaty-Niassar M. Evolution effects of the copper surface morphology on the nucleation density and growth of graphene domains at different growth pressures. Appl Surf Sci, 2017, 399: 542-550

22 Liu L, Zhou H, Cheng R, et al. A systematic study of atmospheric pressure chemical vapor deposition growth of large-area mono- layer graphene. J Mater Chem, 2012, 22: 1498-1503

23 Zhou H, Yu WJ, Liu L, et al. Chemical vapour deposition growth of large single crystals of monolayer and bilayer graphene. Nat Commun, 2013, 4: 2096

24 Lin L, Li J, Ren H, et al. Surface engineering of copper foils for growing centimeter-sized single-crystalline graphene. ACS Nano, 2016, 10: 2922-2929

25 Wood JD, Schmucker SW, Lyons AS, et al. Effects of polycrystalline $\mathrm{Cu}$ substrate on graphene growth by chemical vapor deposition. Nano Lett, 2011, 11: 4547-4554

26 Ross M, Boehler R, Errandonea D. Melting of transition metals at high pressure and the influence of liquid frustration: the late metals $\mathrm{Cu}, \mathrm{Ni}$, and Fe. Phys Rev B, 2007, 76: 184117

27 Shabanova IN, Kholzakov AV, Kraposhin VS. XPS study of transition metal electronic structure in crystalline and liquid states. J Electron Spectr Related Phenomena, 1998, 88-91: 453-455

28 Shabanova IN, Mitrokhin YS. The study of the atomic and electronic structures of liquid copper. J Electron Spectr Related Phenomena, 2004, 137-140: 569-571

29 Laidler KJ, Meiser JH. Physical Chemistry. Boston: Houghton Mifflin, 1999

30 Lin L, Sun L, Zhang J, et al. Rapid growth of large single-crystalline graphene via second passivation and multistage carbon supply. Adv Mater, 2016, 28: 4671-4677

31 Sun L, Lin L, Zhang J, et al. Visualizing fast growth of large singlecrystalline graphene by tunable isotopic carbon source. Nano Res, 2017, 10: 355-363

32 Chen CC, Kuo CJ, Liao CD, et al. Growth of large-area graphene single crystals in confined reaction space with diffusion-driven chemical vapor deposition. Chem Mater, 2015, 27: 6249-6258

33 Babenko V, Murdock AT, Koós AA, et al. Rapid epitaxy-free graphene synthesis on silicidated polycrystalline platinum. Nat Commun, 2015, 6: 7536

34 Guo W, Jing F, Xiao J, et al. Oxidative-etching-assisted synthesis of centimeter-sized single-crystalline graphene. Adv Mater, 2016, 28: 3152-3158

35 Vlassiouk IV, Stehle Y, Pudasaini PR, et al. Evolutionary selection growth of two-dimensional materials on polycrystalline substrates. Nat Mater, 2018, 17: 318-322

36 Geng D, Wu B, Guo Y, et al. Uniform hexagonal graphene flakes and films grown on liquid copper surface. Proc Natl Acad Sci USA, 2012, 109: 7992-7996

37 Guo W, Xu C, Xu K, et al. Rapid chemical vapor deposition of graphene on liquid copper. Synth Met, 2016, 216: 93-97

38 Zeng M, Tan L, Wang J, et al. Liquid metal: an innovative solution to uniform graphene films. Chem Mater, 2014, 26: 3637-3643

39 Li X, Cai W, Colombo L, et al. Evolution of graphene growth on $\mathrm{Ni}$ and $\mathrm{Cu}$ by carbon isotope labeling. Nano Lett, 2009, 9: 4268-4272

40 Zeng $\mathrm{M}$, Tan $\mathrm{L}$, Wang $\mathrm{L}$, et al. Isotropic growth of graphene toward smoothing stitching. ACS Nano, 2016, 10: 7189-7196

41 Ferrari AC, Meyer JC, Scardaci V, et al. Raman spectrum of graphene and graphene layers. Phys Rev Lett, 2006, 97: 187401

Acknowledgements The research was supported by the National Natural Science Foundation of China (21673161) and the Sino-German Center for Research Promotion (1400).

Author contributions $\mathrm{Fu} \mathrm{L}$ and Zeng $\mathrm{M}$ developed the concept and conceived the experiments. Zheng S, Zeng M, Cao H, Zhang T, Gao X and Xiao $\mathrm{Y}$ carried out the experiments. Zheng $\mathrm{S}$ and Zeng M wrote the 
manuscript. Fu L revised the manuscript. All of the authors contributed to the data analysis and scientific discussion.

Conflict of interest The authors declare no competing financial interest.

Supplementary information The supporting information is available in the online version of the paper. (The nucleation density of graphene on $\mathrm{Cu}$ at different temperatures, EBSD characterizations conducted on solidified liquid $\mathrm{Cu}$ and solid $\mathrm{Cu}$, comparison of the growth rate of graphene single crystal between our work and the reported literatures, the growth rate of graphene single crystal grown on solid $\mathrm{Cu}$, effect of diffusion rate on the growth rate of graphene single crystal on liquid $\mathrm{Cu}$, the identification of the effect of the diffusion rate on the growth rate of graphene single crystal on liquid $\mathrm{Cu}$, carbon isotope labeling experiments for elucidating the mechanism and kinetics of the growth of graphene on liquid $\mathrm{Cu}$, the confirmation of the dissolution of carbon in liquid $\mathrm{Cu}$, and the TEM characterizations of the as-obtained graphene single crystal grown on liquid $\mathrm{Cu}$.)

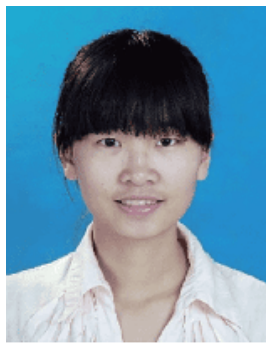

Shuting Zheng received her BSc from the Northwest University in 2016 and is now a master's degree candidate under the supervision of Prof. Lei $\mathrm{Fu}$ at the College of Chemistry and Molecular Sciences at Wuhan University. Her current research interest is the controllable growth of $2 \mathrm{D}$ material

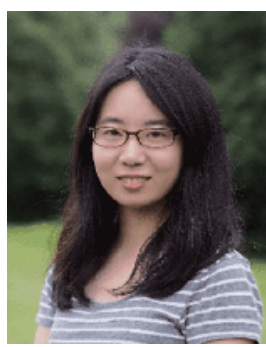

Mengqi Zeng received her BSc from Wuhan University in 2013. She obtained her PhD degree under the supervision of Prof. Lei Fu in 2018 from Wuhan University. In 2018, she joined Wuhan University as an Associate Professor. Her current research interest is the catalyst design for the controllable growth and self-assembly of $2 \mathrm{D}$ materials.

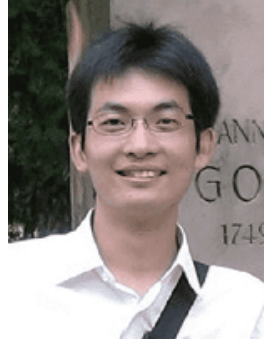

Lei Fu received his BSc degree in chemistry from Wuhan University in 2001. He obtained his $\mathrm{PhD}$ degree from the Institute of Chemistry, Chinese Academy of Sciences in 2006. After obtaining his $\mathrm{PhD}$, he worked as a $\mathrm{Di}$ rector's Postdoctoral Fellow at the Los Alamos National Laboratory, Los Alamos, NM (2006 -2007). Thereafter, he became an Associate Professor at Peking University. In 2012, he joined Wuhan University as a Full Professor. His current interest of research focuses on the controlled growth and novel property exploration of $2 \mathrm{D}$ atomic layer thin crystals.

\section{化学气相沉积法在液态金属上快速生长石墨烯 单晶}

郑舒婷 ${ }^{1}$, 曾梦琪 ${ }^{1 *}$, 曹慧 ${ }^{1}$, 张涛 ${ }^{1}$, 高晓雯 ${ }^{1}$, 肖遥 ${ }^{2}$, 付䂞 ${ }^{1,2^{*}}$

摘要 实现石墨烯大单晶的快速生长对于其未来在光电及电学器 件领域的应用十分必要. 目前已报道的在多晶金属衬底上生长石 墨烯单晶的工作通常是通过降低前驱体供应量从而抑制成核来实 现的, 而这会显著降低成核以及后续生长的速度. 新兴的液态金属 催化剂具有准原子级平滑的表面和高扩散速率. 理论上, 液态金属 是一个天然理想的基底, 可同时实现低密度成核和快速生长. 但截 至目前, 尚无工作探讨液态金属上石墨烯单晶的快速生长. 在本研 究中, 我们成功地在液态铜表面实现了毫米级高质量石墨烯单晶 的生长. 液态铜中丰富的自由电子能加速石墨烯的成核, 且其各向 同性的平滑表面能显著抑制成核, 使得成核密度较低. 更重要的是, 由于液态铜优异的可流动性, 前驱体碳原子能实现快速扩散, 这极 大促进了石墨烯的生长, 最高速率可达 $79 \mu \mathrm{m} \mathrm{s}^{-1}$. 我们希望这一关 于液态铜体系中石墨烯生长速率的研究能丰富研究者们对液态金 属上二维材料生长行为的认知. 我们也相信利用液态金属来实现 石墨烯快速生长的策略能被拓展至其他二维材料, 由此来促进它 们在未来光电以及电学器件领域的应用. 